\title{
Covert social movement networks and the secrecy-efficiency trade off: The case of the UK suffragettes (1906-1914) (2) $^{\text {th }}$
}

\author{
Nick Crossley*, Gemma Edwards, Ellen Harries, Rachel Stevenson \\ Mitchell Centre for Social Network Analysis, School of Social Sciences, University of Manchester, UK
}

\section{A R T I C L E I N F O}

\section{Keywords:}

Covert networks

Secrecy-efficiency trade off

Social movements

Suffragettes

\begin{abstract}
A B S T R A C T
This paper formulates and empirically tests a number of hypotheses regarding the impact of covertness upon network structure. Specifically, hypotheses are deduced from theoretical arguments regarding a 'secrecy-efficiency trade off' which is said to shape covert networks. The paper draws upon data concerning the UK suffragettes. It is taken from a publicly archived UK Home Office document listing 1992 court appearances (for suffrage related activities), involving 1214 individuals and 394 court sessions, between 1906 and 1914. Network structure at earlier phases of suffragette activism, when the movement was less covert, is compared with that during the final phase, when it was more covert and meets the definitional criteria of what we call a 'covert social movement network' (CSMN). Support for the various hypotheses tested is variable but the key claims derived from the idea of the secrecy-efficiency trade off are supported. Specifically, the suffragettes' network becomes less dense and less degree centralised as it becomes more covert.
\end{abstract}

(C) 2012 Elsevier B.V. All rights reserved.
The threat posed by terrorism and, more particularly, the increased estimation of that threat in the wake of 'al-Qaeda'1 attacks across the world has generated a flurry of interest, both academic and political, in so-called 'covert', 'clandestine', 'underground' or 'dark' networks (e.g. Klerks, 2001; Krebs, 2001, 2002; Carley et al., 2003; Raab and Milward, 2003; Sageman, 2004, 2008; Tsvetovat and Carley, 2005; Koschade, 2006; Enders and Su, 2007; Morselli et al., 2007; Stohl, 2008; Lindelauf et al., 2009; Morselli, 2009; Rodriguez, 2009). Much of the work to date has been based on simulations, (game) theoretical models and speculation. Relatively little has been empirical (Rodriguez, 2009; Asal and Rethemeyer, 2006). Moreover, as we discuss further below, what data exist, with a few exceptions (e.g. Baker and Faulkner, 1993; Morselli, 2009), are very limited.

In this paper we increase the evidence base on one type of covert network: the 'covert social movement network' (CSMN). We regard a network as a social movement network if its members collectively identify with a project of social/political change and if at least some of them engage in activities intended to bring it about (see also Crossley, 2007; Diani and McAdam, 2003). Usually this will involve

\footnotetext{
it Thank you to Martin Everett, Tom Snijders and our anonymous referees for their very helpful comments on earlier drafts of this paper.

* Corresponding author. Tel.: +4401612752517.

E-mail address: nick.crossley@manchester.ac.uk (N. Crossley).

1 We use this name broadly to refer to contemporary radical Islamic groups and networks engaged in political violence.
}

a form of protest activity and it extends to networks whose members engage in political violence and who are sometimes therefore deemed terrorists. Terrorist networks are a subset of CSMNs.

What makes a network covert is more difficult to specify. One of our criticisms of the literature on covert networks is the failure of contributors to unpack this concept or discuss its facets and associated practices (although see Goffman, 1959, 1969; Simmel, 1906). Different aspects of a network and its activities may be subject to secrecy and there may be variation as to who keeps them secret, from whom and at what points in a cycle of activity. Most human relationships involve some level of secrecy (ibid.) but no networks that we know of are completely secret - by definition. Moreover, some 'covert' networks, including CSMNs, strive as much for publicity as for secrecy - Osama Bin Laden's regular video statements being an obvious example. They seek to make claims in the public sphere regarding their existence, beliefs, demands and involvement in activities. Indeed, in the case of al-Qaeda the identity and public profile of their leader is or rather was central to their modus operendi. What was secret was his location.

Furthermore, there are significant variations in how covertness is achieved. To give one example, a meeting may be kept secret by holding it in a remote location, out of sight and earshot, but activists might equally well use very visible everyday activities and relations, such as friends meeting at a barbeque, as camouflage. Likewise, groups may achieve secrecy through physical separation and hiding, as when on the run, or by running double lives and practicing an extreme form of the 'impression management' that both Goffman $(1959,1969)$ and Simmel (1906) deem integral to all social 
interaction and relations. Such variations are important because if covertness affects network structure, as some believe (see below), it may do so differently according to the forms it assumes.

These issues need further discussion. For present purposes, however, our interest is in networks whose members: (1) commit illegal acts whose details must be kept secret from the authorities prior to their commission; and who (2) seek to remain anonymous to all but a select few after their commission. The participants involved in given actions are the focus of secrecy in this case. The secret is kept by those participants and perhaps a small number of others from everybody else. And for as long as the secret holds those in the know lead a double life, mixing with the same number and range of alters that they otherwise would. If the secret is broken, however, and they become wanted by the police, then they may go on the run, in which case it will be their whereabouts that become secret rather than their involvement in the aforementioned acts.

The CSMN focused upon in this paper is that of the UK suffragettes (1904-1914). Though they meet the first of our above criteria throughout their history, the suffragettes only meet our second criteria in the final phase of their campaign (1913-1914). This shift in their modus operendi affords us an opportunity to explore the effects of covertness and to test key hypotheses from the literature. Before we can do this, however, we must briefly review that literature.

\section{The secrecy-efficiency trade off}

CSMNs potentially raise a wide range of questions for network analysis and number of distinct hypotheses have been made in the literature. In this paper we focus upon hypotheses regarding the socalled 'secrecy-efficiency trade off'. Assuming that secrecy can only be achieved in a network at the expense of efficiency, advocates of the trade-off idea argue that the desire for secrecy within networks involved in illegal activities often overrides the desire for efficiency and that this impacts upon network structure. Specifically, covert networks are said to be characterised by low density and (degree) decentralisation (Baker and Faulkner, 1993; Enders and Su, 2007; Klerks, 2001; Krebs, 2002; Lindelauf et al., 2009; Morselli et al., 2007; Raab and Milward, 2003; Rodriguez, 2009).

Who makes this trade off and how it brings about the specified effects is nowhere spelled out but the implication appears to be that activists seek to minimise their connections to one another, resulting in low density, because they become more vulnerable to discovery and arrest with each tie that they maintain. Any one of their contacts may be compromised and may, in turn, compromise them. Following this logic we would also expect average degree within covert networks to be relatively low. For the same reason, moreover, leaders and other key actors seek to avoid becoming centralised hubs, thereby keeping degree centralisation low.

These claims are plausible but they are problematic as predictions about network structure. We have identified a number of problem areas which need to be addressed. These can be subsumed under five headings.

\subsection{Definitions and measures}

No definitions of or benchmarks for high/low density/centralisation are given and the magnitude of these measures is notoriously difficult to gauge ${ }^{2}$ because each is dependent on the order of a network and the type of relationship involved.

\footnotetext{
2 This is especially true of density. The magnitude of centralisation of a network could be assessed by comparing empirical networks against random simulations or a maximally centralised network with the same order and density. Such methods are not without problems, however.
}

This makes testing very difficult. Unless we have comparisons or benchmarks we have no robust basis upon which to deem networks sparse or decentralised. And where networks are large ${ }^{3}$ or geographically dispersed, as many CSMNs are, they will often have a low density (compared to smaller and geographically concentrated networks) for these reasons alone.

In addition, although one can infer that claims regarding centralisation refer to degree centralisation this is seldom specified and, with the exception of Morselli (2009), there is no discussion of other forms of centrality and centralisation. This is problematic because degree centralisation is not the only form of network centralisation and other forms may be equally or more pertinent in relation to covert networks. Morselli's (2009) work on criminal networks, for example, shows that whilst leaders in a covert network seek to avoid a high degree their desire for control within and of the network leads them to carve out a betweeness central position.

Furthermore, there is some slippage in the literature between network-analytic definitions of centralisation, focused upon graph properties, and definitions focused upon the existence of leadership roles and legitimate authority. Some authors equate covert networks with anarchist networks whose members refuse to accept any authority structure, describing the networks in question as 'decentralised' upon this basis. This is problematic, on the one hand, because not all covert networks are anarchist in orientation. Paramilitary organisations such as the Provisional Irish Republican Army (PIRA), for example, often combine covertness with a concern for military discipline and authority structures (Stevenson and Crossley, forthcoming). More problematic from our viewpoint, however, is the conflation of political and network (degree) centralisation in these discussions. Political and degree decentralisation are not equivalent. Leaders might exist and exercise their authority in a network, without occupying a central position with regard to degree. Conversely, central (by any measure) positions in highly centralised networks are not always leadership positions. That depends upon the type of tie involved (e.g. does it entail authority?), exogenous factors such as the occupant's control over scarce resources (Erikson, 1981) and the occupant's willingness and ability to play the leader role (i.e. their agency).

Notwithstanding this, however, some accounts fruitfully combine considerations of political and network (degree) decentralisation, without conflating the two, in a manner which proves very relevant to our later analysis. Sageman's (2008) discussion of 'leaderless resistance' is particularly relevant (see also Garfinkel, 2003, and for an advocates view Beam, 1992). Leaderless resistance involves multiple individuals or small cells, inspired by a common cause but otherwise either unconnected or (in contemporary cases) connected only by anonymous virtual communications, acting independently in pursuit of that cause. Each cell thus forms a distinct component in the movement network, a structure which maximises secrecy/security because the independence of cells removes the possibility that one might compromise another. It minimises efficiency, however, because structural holes between cells prevent coordination. Individual cells are often ignorant of one another's existence and, as such, cannot act in concert.

\subsection{Evidence base}

Most of the work on the trade off involves theoretical models which are neither constructed nor tested by reference to empirical data. Very little empirical work has been done. Moreover, that which has been done on CSMNs tends to be exclusively focused upon a single case study, contemporary Islamic militancy, and is,

\footnotetext{
${ }^{3}$ Example: with an order in the thousands.
} 
in most cases, focused upon a set of actors involved in a single operation, what Barnes (1971) calls an action set, rather than the wider network to which that action set belongs (Krebs, 2001, 2002; Koschade, 2006; Rodriguez, 2009, an exception is Sageman, 2004). Indeed, almost all of those who claim empirical support for the trade off idea draw exclusively upon a single study of a single action set: Krebs' $(2001,2002)$ study of the network of those activists publicly identified as being involved in $9 / 11$. This is problematic because we do not know how typical that action set is and because an action set is only a small (and often expendable) subset of a wider network whose structure may bear little resemblance to that of the action set.

Better data and analyses are available in relation to criminal networks (Baker and Faulkner, 1993; Morselli, 2009). However, this work does not straightforwardly support the trade off idea. Although, as noted, orders of magnitude are difficult to determine, covert criminal networks are not obviously sparse or decentralised, forcing those who research them and who advocate the trade off idea to claim an exception for them. Baker and Faulkner (1993), for example, argue that although decentralised structures are best for both maintaining secrecy and accomplishing complex tasks, when taken separately, higher centralisation is necessary if both secrecy and the accomplishment of complex tasks are required simultaneously: 'Operating a high-information conspiracy in a decentralised manner is infeasible because face-to-face interaction and involvement of top executives are necessary to make complex decisions in secret' (Baker and Faulkner, 1993, p. 854). In a different vein, Morselli et al. (2007, Morselli, 2009), who compare their findings on a drug trafficking network with Krebs' data, argue that the material incentives which drive criminal activity demand quicker returns than the ideological incentives which drive social movement activity and thus both greater efficiency and the centralisation necessary to achieve it. Criminal networks operate according to a different temporal structure for Morselli et al. which disinclines their members from trading efficiency for secrecy.

These qualifications are entirely plausible but we doubt that they apply exclusively to criminal networks. Many CSMNs are engaged in highly complex operations and require the same level of efficiency as organised criminal networks. Similarly, most are constrained by material and temporal demands which generate a further desire for efficiency. Like all social movements they need to mobilise significant resources to remain active (Crossley, 2002; Jenkins, 1983). And because covert - and therefore often cut off from legitimate sources of income - they may resort to criminal activity to do this, blurring the distinction between criminal and social movement networks. It is widely noted, for example, that PIRA were involved in both bank robbery and smuggling in order to maintain their resource flows (Adams, 1986; Harnden, 1999). Furthermore, it is often imperative for both social movement organisations (SMOs) and individual activists to be able to respond quickly to the actions of opponents and competitors, again generating temporal pressures and a demand for efficiency.

We do not mean to deny that there are differences between CSMNs and other types of covert network, such as criminal networks, nor indeed differences between individual CSMNs. The grievance-based drivers of social movement activity do affect practices, as martyrdom operations indicate, and CSMNs are usually not concerned with material resources for their own sake, which may also make a difference to their activities. However, efficiency, speed and material resources are still very important to them. If the perceived need for efficiency in operations sometimes leads criminals to refuse to trade it for secrecy then we might expect the same in CSMNs. The exceptions which Baker and Faulkner (1993) and Morselli et al. (2007) claim for criminal networks, in relation to the prediction of the secrecy-efficiency trade off, may not be exclusive to such networks and may apply to CSMNs.

\subsection{Variation and multiplexity}

These observations do not completely undermine the trade off idea but they suggest that the relative importance of efficiency and secrecy may vary in accordance with the activities of network members, perhaps therefore with network neighbourhoods and perhaps also across time. Enders and Su (2007), for example, suggest that networks may decentralise and reduce density (i.e. reduce active ties) at certain points in time in response to a perceived increase in their risk of compromise.

Furthermore, structure may vary in accordance with tie types and with the goods flowing through a network. Many CSMNs are multiplex and, as such, manifest a multi-dimensional structure, irreducible to a single set of measures. Within the suffragettes, whom we discuss below, for example, financial flows were highly centralised; most of the money passed firstly to the HQ of the dominant SMO, the Women's Social and Political Union (WSPU), only then flowing out again to activists (Rosen, 1974). Face-to-face ties between grassroots activists, by contrast, appear to have been much less centralised (Stanley and Morley, 1988; Purvis, 1995). Likewise, whilst information about forthcoming actions was usually circulated on a need-to-know basis, generating a small and dense sub-network, other information passed freely between large numbers of interested parties.

\subsection{Competing and conflicting arguments}

More problematically, equally plausible arguments have been made predicting that CSMNs will be highly centralised and dense. The centralisation argument hinges on the claim that security in a network is compromised when decisions or resources traverse long paths. Each transaction in a chain represents a risk of compromise, it is argued, and paths will therefore be kept short (see Fig. 1). One way to achieve this would be for networks to have a high density but that is risky (for the reasons outlined above). The alternative is for all activity to be co-ordinated by a centralised hub which maintains direct contact with all operatives (Lindelauf et al., 2009). The argument for high density, by contrast, is that it is more conducive to the generation and maintenance of solidarity, oppositional outlooks/identities and incentives for self-sacrifice, such as are typical in CSMNs (Coleman, 1988, 1990) or alternatively, following Erikson (1981), that members of CSMNs will recruit primarily from amongst those with whom they already enjoy a relation of trust (pre-existing ties); that is, friendship ties which, following Granovetter $(1973,1983)$, we would expect to form relatively dense and transitive localised clusters.

We believe that these differences of opinion reflect different assumptions about the likelihood of a network being compromised. Those who predict low density and decentralisation in CSMNs make their case by identifying the advantages of these properties in situations where one or more actors in a network are compromised. The potential damage caused by any such compromise is minimised, they suggest, when actors have relatively few ties and leaders in particular protect themselves if they avoid becoming a hub. Advocates of high density or centralisation, by contrast, make their case by suggesting that these properties reduce the likelihood of compromise in the first place. In addition, they view efficiency and secrecy as compatible goals which do not need to be 'traded'. To preserve its secrecy, they believe, a network must be efficient (see also Simmel, 1906).

Note that both the high and low density arguments are accommodated, to some extent, by localised clustering in a globally sparse network. Dense clusters constrain actors, affording security, 


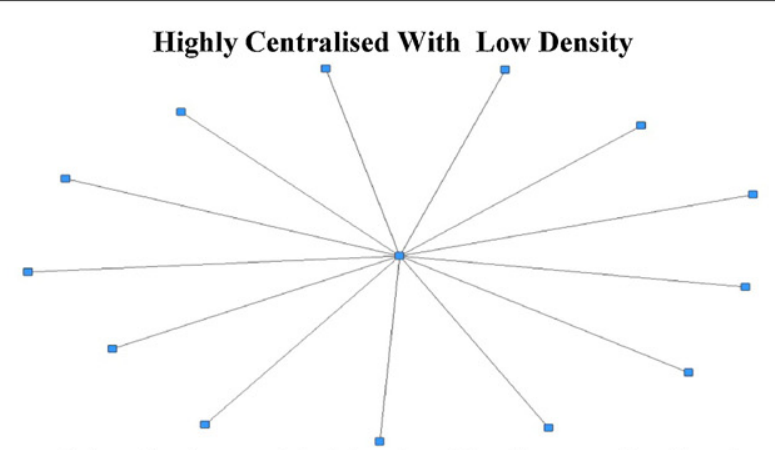

The centre keeps path lengths short, minimising the risk of interception, but the centre is vulnerable to detection because each of its many contacts poses a risk of compromise.

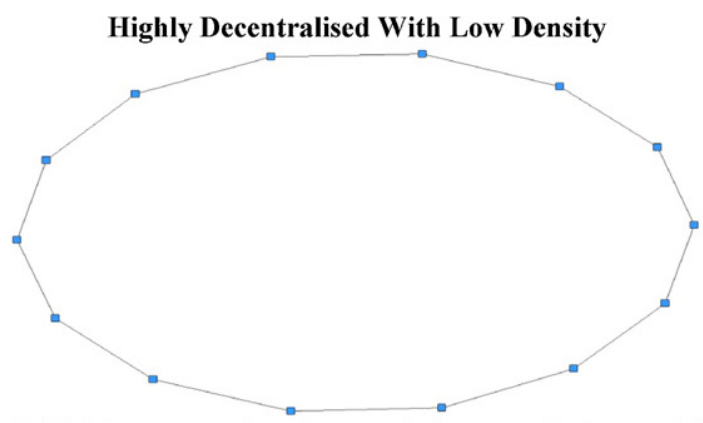

Individual security is high because each node can only betray or be betrayed by two others but the network may be compromised because a transfer of resources from one side of the network to the other will involve a lot of transactions, each of which adds to the risk of detection. For the same reason the network is inefficient.

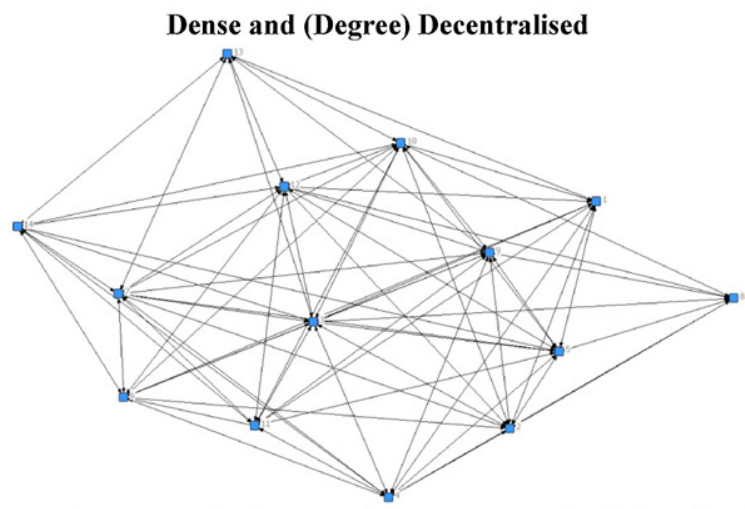

High levels of contact between nodes increase the support to and policing of each, enhancing security, generating solidarity and perhaps reinforcing militant views, but each node is known by a relatively high number of others who may compromise her, threatening security.

Fig. 1. Three idealised network structures and their security pros and cons.

maintaining trust and facilitating the maintenance of 'deviant' frames and incentive structures, but if ties between clusters are sparse then the possible damage caused by infiltration and arrest is contained and thus minimal. This balance is sometimes implied in discussions of 'cell structure' (Sparrow, 1991). Although cell structure can be envisaged differently (including centralised, decentralised and 'leaderless' forms ${ }^{4}$ ), all variants involve localised

4 Some versions of a cell structure overlap with the leaderless resistance idea discussed above or with the more connected but no less degree centralised webs of overlapping anarchist affinity groups. Such structures are decentralised in both political and network (degree) terms. Others are more hierarchical, however, with individual cells serving as 'pawns', directed from without and largely ignorant of the density (within cells) combined with global sparseness (between cells).

\subsection{Design limitations}

Finally, arguments about the trade off tend to assume that covert networks reflect a 'design', affording almost no attention to the multiple obstacles and contingencies that shape even those networks which are in some way 'designed' and not, as many networks are, an unintended outcome of actions motivated by quite

wider network. These are politically centralised and probably also more centralised in terms of either degree or betweeness. 
different purposes (Coleman, 1990). Degree decentralisation is difficult to engineer, for example, because nobody can coordinate it without becoming central. Centralisation, by contrast, is difficult to achieve unless those at the centre monopolise important resources which afford them leverage over the actions of others (Erikson, 1981). And attempts to achieve centralisation can precipitate splits, leading to fragmentation and decentralisation. Moreover, though it may be possible to keep density of regular contacts low if everyone is following the same 'script' (a big 'if' when actors are not in contact and cannot discuss or agree a script), activists cannot control who they meet or already know, cannot 'unlearn' contacts they have made and may be disproportionately likely to meet and form ties in virtue of their convergence upon common, movementrelated 'foci' (Feld, 1981, 1982). Activists' common interests will often draw them towards the same protest events, training camps and radical meetings, for example, where they will meet and form bonds. It may also land them in prison together, again facilitating tie formation. And there is an extensive literature suggesting both that many social movements grow out of pre-existing networks of dense ties and that such networks are key recruitment channels (see Crossley, 2007 for a review), such that they inevitably inherit structures which are not of their own making or design (Erikson, 1981).

Historical accounts of PIRA, which adopted a cell structure in the 1970s in a bid to improve internal security, point to many such problems (Maloney, 2002; Harnden, 1998). Apart from the fact that some brigades, including the most effective and impenetrable South Armagh Brigade, refused to move to the new cell structure, and excepting those cells operating on the British mainland, whose members were isolated from other cells by geographical distance, cell structures were difficult to maintain because they were embedded in wider and dense community and family networks which cross-cut them and whose members were sufficiently 'in the loop' to make PIRA membership an open secret.

\section{Moving forward}

Notwithstanding these problems, the trade off theory is interesting, plausible and commands considerable support in the literature. To move the debate forward we need more data, covering a wider range of cases and tie types, which allow us to test it in a meaningful way and, where necessary, to refine it.

In what follows we make a start on this by presenting and analysing a dataset concerning the UK suffragettes. This is just one dataset, concerning one CSMN. And like all data on covert networks it has significant flaws. However, it is an important dataset both in the respect that it concerns a CSMN which has not previously been considered in debates on covert networks and in the respect that it affords us an opportunity for testing certain key hypotheses which we can deduce from the literature discussed above.

Furthermore, although there has been very little networkanalytic research on the UK suffragettes ${ }^{5}$ there is a large body of historical/sociological scholarship ${ }^{6}$ and there are a number of widely accepted reference works (e.g. Crawford, 1999). We have drawn upon both in an effort to contextualise and organise our data and also to reflect critically upon their validity. In particular, whilst there are important disputes within this literature, there is a basic agreement about the development and escalation

\footnotetext{
5 The same is true of other countries too. However, on the USA see Rosenthal et al. (1985). The only network analytic research on the UK suffragettes that we are aware of is (Edwards and Crossley, 2009; Edwards, forthcoming).

${ }^{6}$ There are too many works to cite here. In what follows in the paper we cite those works which have been of specific use and value for our purposes, where it is most pertinent to do so.
}

of militancy, and there are many good biographies and case studies concerning militant and covert activities (e.g. Mitchell, 1977; Purvis, 2002; Raeburn, 1973; Stanley and Morley, 1988). We have drawn extensively upon this literature at all stages of our work, in an effort to increase validity, and have used it to cross-check our findings. With this said we can introduce the case study.

\section{The UK suffragettes: a CSMN?}

Active between 1903 and 1914, the suffragettes distinguished themselves from other women's suffrage campaigners by their willingness to break the law in pursuit of their cause. ${ }^{7}$ The purpose of their law breaking shifted in the course of their campaign, however, as did their level and practices of covertness. In the early phases of their campaign they broke the law in order to be arrested, tried and imprisoned, rejecting alternatives when they were offered. Arrests and trials were valuable outcomes because they generated a great deal of publicity on a regular basis. And the imprisonment of often well-to-do women had an enormous symbolic impact in Edwardian Britain, generating a great deal of sympathy and material support for the suffragettes' cause (Holton, 1988; Phillips, 2003). This impact increased considerably, furthermore, when, from 1909 onwards, many imprisoned suffragettes went on hunger (and occasionally thirst) strike, protesting for their right to be treated as political prisoners; and when, between 1909 and 1913, many hunger striking suffragettes were force fed. The details of force feeding, which involved women being strapped to a seat or bed and having tubes forced down their throat or sometimes up their anus, were deeply shocking to many observers.

Whilst the planning of law breaking activity was usually secretive and operated on a need-to-know basis during the early phases of the campaign, therefore, there was no attempt to hide the identity of perpetrators after an illegal action. A small number of activists used pseudonyms to avoid damaging the reputations of their husbands/families (the vast majority of activists were women) and some timed their actions to allow their imprisonment to fall within work holidays, so as to keep their involvement from employers, but illegal activity was intended to achieve arrest and most were arrested under their own name. Whilst the suffragettes meet our first criteria for a CSMN in the early phases of their campaign, therefore, they do not meet our second criteria; that is, whilst they (1) committed illegal acts whose details were kept secret from the authorities prior to their commission; they did not (2) seek to remain anonymous to all but a select few after the commission of these acts.

As efforts to control the suffragettes increased, however, with measures including the formation (in 1909) of a dedicated section of Special Branch, the police's undercover anti-extremism unit, the suffragettes became increasingly covert (Raeburn, 1973; Rosen, 1974). And it is widely acknowledged by suffragette historians that there was a clear step change in tactics during 1913 and 1914, the final two years of their campaign (ibid.). As we discuss below, forms of law breaking became more serious, to include a sustained campaign of arson and bombing, and suffragettes no longer presented themselves for arrest (ibid.). They sought to both avoid arrest and remain anonymous. Furthermore, when the government, keen to avoid the deaths of hunger striking suffragettes in custody, introduced a system of releasing them under house arrest (with surveillance), many of those involved either used the opportunity to escape and go on the run or employed anti-surveillance tactics to evade police 'watchmen' and remain active. Stories abound, for example, of suffragettes sneaking out of the houses in which they were supposed to be imprisoned in order to take part in

\footnotetext{
The enfranchisement of women but as a first step towards greater gender equality and improvement of women's lives more generally.
} 


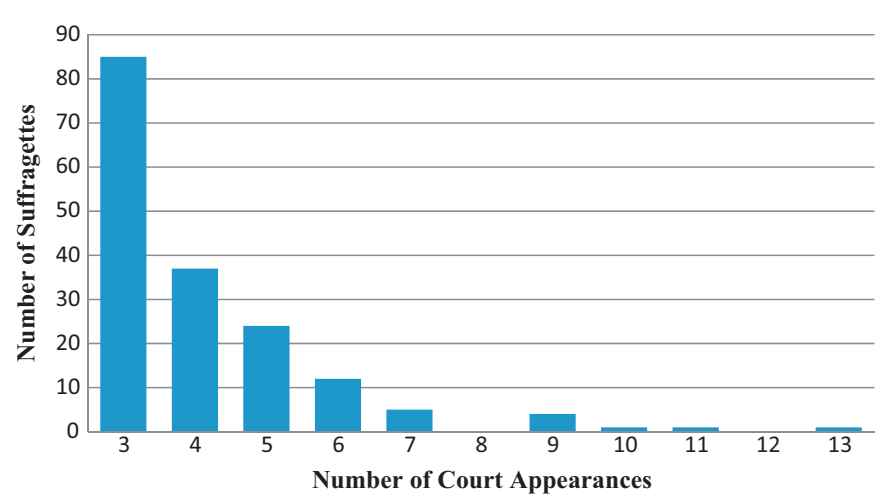

Fig. 2. Numbers of court appearances for suffragettes with $>2$ appearances.

further illegal actions or rallies (where, along with fugitives, they were sometimes presented to delighted crowds before disappearing again) (Raeburn, 1973). In the period 1913-1914 therefore, the suffragettes meet both of our criteria for a CSMN: they both (1) committed illegal acts whose details were kept secret from the authorities prior to their commission; and (2) sought to remain anonymous to all but a select few after the commission of these acts.

Following trade off theory, as outlined above, we would expect this increased concern with secrecy and anti-surveillance measures to result in a reduction of contact between activists (including organisers) and thus a reduction in the density, average degree and degree centralisation of the network of those involved. In what follows we describe data which allow us to test this.

\section{Data}

Shortly after the First World War the UK Home Office compiled a handwritten file, now publicly archived, which purports to list all individuals (alphabetically) who appeared in court for suffragetterelated activities between 1906 and 1914 (inclusive), followed by the date and place of their various court appearances (Home Office, 1922). Though this file is incomplete it is extensive and by far the best quantitative record of illegal activity by the UK suffragettes. It identifies 1214 individuals, mostly women, who appeared in court a total of 1992 times, across 394 separate court sessions. The majority of individuals made only one (69\%) or two (17\%) appearances but many appeared on four or more occasions. The maximum number of appearances was 13 (see Fig. 2) and the mean number of suffragettes per trial was 5 .

Using this file we constructed incidence matrices of defendants and court sessions, from which we derived single mode adjacency matrices linking prisoners who appeared in court together and who we know, therefore, ${ }^{8}$ participated in the same action (all matrix manipulation and subsequent network analysis was performed using Ucinet (Borgatti et al., 2002)). The ties we are measuring, therefore, involve co-participation in protest action ('action ties').

Our key concern was to compare the 1913-1914 phase of the campaign, when the suffragettes became fully covert by our definition, with what went before it but the earlier 'phase' extended back eight years (six of which were covered by our data) and it was clear from the wider literature that there were several distinct phases within it, marked both by surges in activity and tactical shifts (Raeburn, 1973; Rosen, 1974; Van Wingerdon, 1999). We could not simply compare the 1913-1914 period with what went before,

\footnotetext{
${ }^{8}$ Suffragettes were only tried together in instances where they had been arrested
} together; that is to say, in the course of engaging in the same actions.

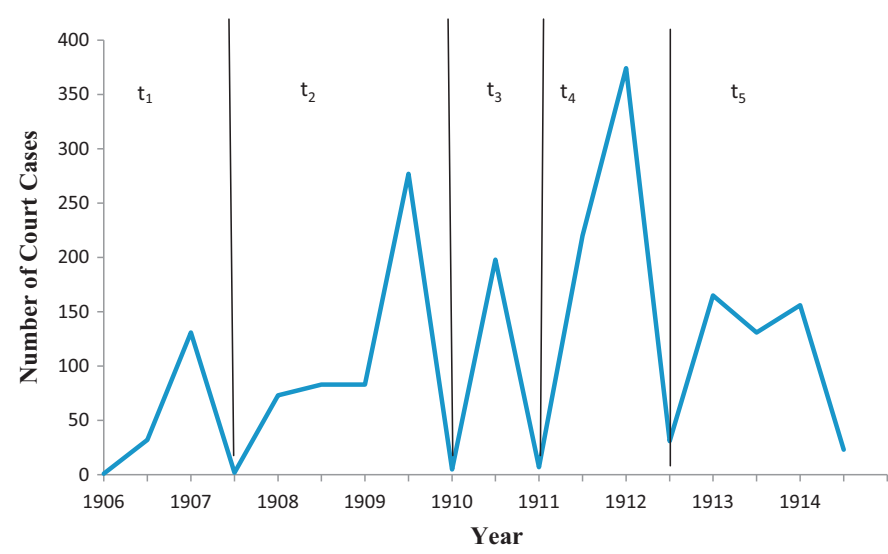

Fig. 3. Frequency of court appearances for suffragette-related offences in the UK, 1906-1914.

therefore, because what went before was not a single, homogenous wave of activism.

To deal with this we plotted arrest numbers at different intervals, attempting to find an interval whose plot corresponded with historical accounts of the various phases of the campaign. Six monthly intervals proved the best fit and suggested that suffragette activism could be divided into five distinct phases, each characterised by a peak in arrest numbers and separated by troughs (see Fig. 3). We divided the data accordingly, generating five (temporally) distinct networks for comparison.

The dips in early 1910 and early 1911, charted in Fig. 3, reflect truces called by the WSPU in response to government bills which, if passed, would have introduced voting rights for a small number of women (the other main militant SMO, the Women's Freedom League (WFL), did not call a truce but its members may have informally supported it). The spikes immediately following these dips represent the backlash of the suffragettes when, despite considerable support for the bills, the government prevented their passage.

The dip in the first part of 1912 and subsequent spike in the second part of that year may reflect suffragette responses to a third bill and its (similar) fate, although there was no official truce on this occasion and many suffragettes were distrustful of the government by this point. It may also reflect the aftermath of the spike of late 1911. Many suffragettes were still in prison or recovering from hunger strikes and force feeding at this point and therefore unable to participate in any action. Furthermore, it may reflect a temporary shift of focus within the WSPU leadership towards internal matters; two key organisers were expelled at this time, an act which reflects internal controversy and which also caused much controversy.

Internal conflict may also partly explain the dip in mid 1907. In September of that year the breakaway WFL was formed, reflecting internal tensions that had been evident throughout the year. The summer recess in Parliament is also a factor, however. The early illegal activities of the suffragettes often focused upon parliament and could only be carried out when it was sitting. Finally, the huge growth in public profile and offers of support generated by the activities in the first spike, which must have taken the WSPU by surprise and overwhelmed what was, at that time, a relatively small organisation, may also partly explain the dip. The WSPU may have struggled, initially, to cope with a large and sudden surge in numbers.

What is not captured in Fig. 3 is a widely documented escalation in militancy (ibid.). Law breaking during $t_{1}$ was restricted to the disruption of (usually Liberal Party) political meetings, with technical assaults on police officers sometimes included as a means of assuring arrest (Holton, 1988; Van Wingerdon, 1999). In $t_{2}$ attempts by (usually small) deputations, often embedded in larger 


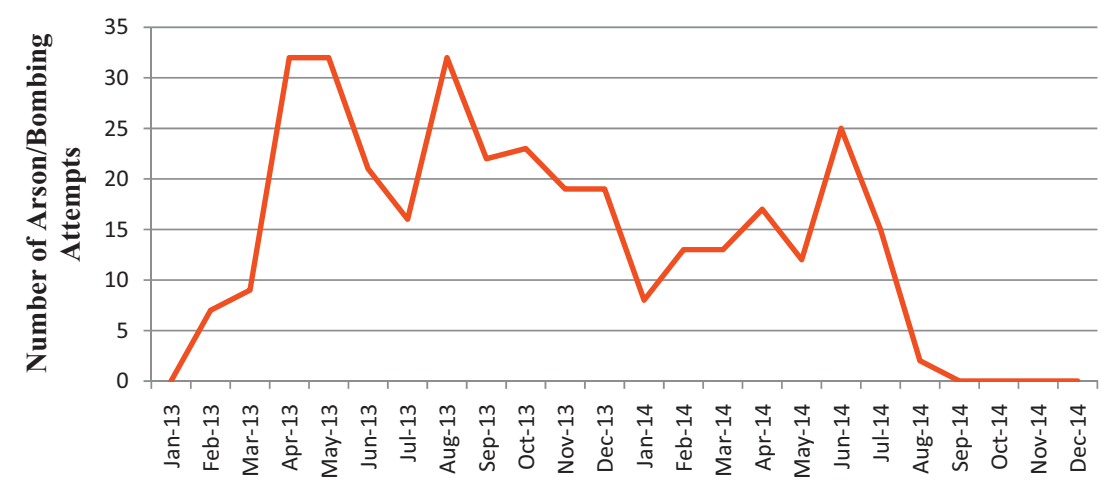

(Source: Bearman 2005)

Month/Year

Fig. 4. Bomb plots and arson attributable to the suffragettes, 1913-1914.

demonstrations, to break police lines and gain access to politicians were added to the repertoire, as were physical attacks on certain politicians (ibid.). In $t_{3}$ the suffragette's repertoire extended to include smashing windows of government buildings (though Mary Leigh and Edith New were arrested for this as early as 1908, the former announcing in court that 'it will be bombs next') (Rosen, 1974). And in $t_{4}$, window smashing extended to commercial properties and was joined both by destruction of the contents of postboxes (by fire, acid or ink) and a first wave of arson attacks on unoccupied buildings. During $t_{5}$ the strategy of causing criminal damage was extended to works of art and sports facilities (Fowler, 1991; Kay, 2008). Theatres and religious services were disrupted (Mitchell, 1977; Smith, 1998). And there was an extensive campaign of arson and bomb planting (Bearman, 2005; Rosen, 1974; see Fig. 4). Earlier methods (including legal methods) were not abandoned as new ones were introduced. Moreover, many non-militant SMOs maintained a campaign of legal protest throughout 1906-1914. The militants were clearly upping the ante at each successive phase between $t_{1}$ and $t_{5}$, however.

Although there had been rumours of an assassination attempt on Prime Minister Asquith as early as $t_{2}$ (recently released archive documents include surveillance reports of WFL members practicing with handguns) and though politicians were sometimes physically assaulted, most of the damage was deliberately targeted on property only. However, this has not prevented some from arguing, controversially, that the suffragettes became 'terrorists' in 1913-1914 (Bearman, 2007a; Monoghan, 2000).

Also missing from Fig. 3 is any indication of the number of court cases (as opposed to the number of suffragettes tried) in each period. As Fig. 5 indicates, the number of individual court cases

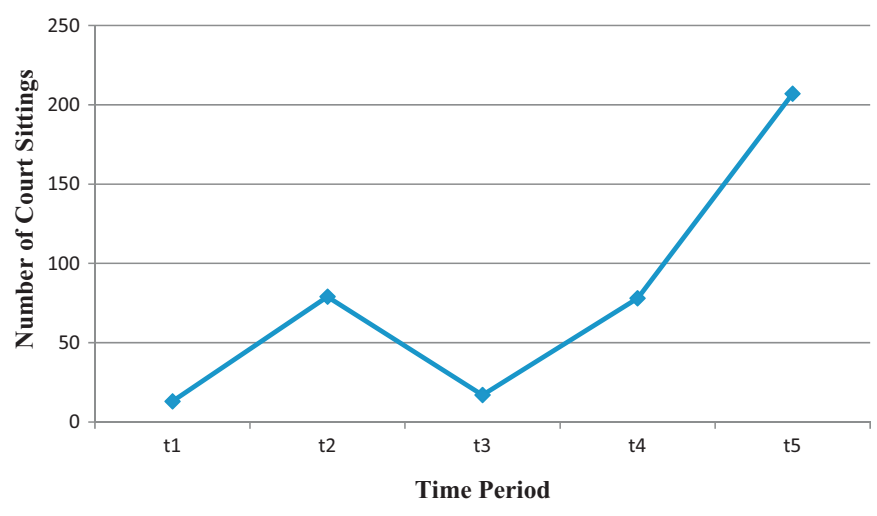

Fig. 5. Court sessions involving suffragettes. increases considerably during $t_{5}$. Illegal action was proliferating as well as escalating during $t_{5}$.

The covertness of the suffragettes is more difficult to pin down. They had used various techniques of covert operation, from pseudonyms, through codes and ciphers to disguise, from very early in their history. And like all social actors they sought to control the flow of information regarding their activities for strategic purposes (Simmel, 1906; Goffman, 1959, 1969). Deputations were more effective and meetings more easily disrupted, for example, when they took targets by surprise, a condition which required more effort and better counter-surveillance practices as police intervention intensified and became more pro-active. Likewise, activists wanted to be portrayed in a certain light to maximise the symbolic impact of their actions and needed to control information flow to achieve this (Mitchell, 1977). However, as noted above, there was a step change in covertness in $t_{5}$ which provides us with the opportunity to test the idea of the secrecy-efficiency trade off. It had two aspects.

Firstly, having acted with the intention of being arrested and imprisoned during $t_{1-4}$, often waiting at the scene for police to arrive, in $t_{5}$ suffragettes more often sought to evade arrest (Raeburn, 1973; Rosen, 1974). The reason for this shift, presumably, was that some were now committing offences carrying longer prison sentences whose costs to both individual and movement outweighed their symbolic benefits. The arrest, imprisonment, hunger strikes and force feeding of often very 'respectable' women generated considerable support, both material and symbolic, for the suffragettes. Rosen (1974), for example, shows how both donations to the WSPU and new memberships grew enormously following each of the first three moments of escalation. These benefits would have been outweighed, however, as sentences lengthened. Prison was a traumatic experience for many, particularly where hunger striking and force feeding were involved. Furthermore, many women had commitments and responsibilities in other (e.g. family) networks outside of the suffragette movement, which could not easily endure prolonged absence. And the movement too needed to keep committed activists in circulation. It needed protest on the streets if political pressure was to be maintained. A more covert approach therefore made sense at this point.

The second factor inducing an increase in covertness was the introduction of the 1913 Prisoner's (Temporary Discharge for IllHealth) Act, popularly known as the 'Cat and Mouse Act'. This act allowed for hunger striking suffragettes to be temporarily released on licence until they were well enough to be re-arrested and returned to prison to complete their sentences; a process which critics likened to the way in which cats release injured prey only to leap on them again before they fully escape. The purpose of 
the act was to prevent any deaths in custody, which would have threatened the legitimacy of the government's stance, and it was believed that suffragettes would be both too weak to participate in protest when released and then easily re-arrested when recovered. In practice, however, some suffragettes sought to evade re-arrest, effectively going underground and on the run, whilst others became sufficiently well-versed in counter-surveillance to remain active without alerting those charged with observing them. One account, for example, relates how a suffragette swapped clothes with a male visitor to her house (where she was under house-arrest), leaving arm in arm with the man's wife, unnoticed and heading straight for a meeting, right under her police observer's nose (Raeburn, 1973). The 1913 act was a 'cat and mouse' act in more ways than one.

Whilst we do not believe that 'covertness' is a uni-dimensional or discrete property and whilst we would emphasise that by no means every suffragette arrested in $t_{5}$ was an arsonist or fugitive 'mouse', therefore, there was a clear change in strategy in $t_{5}$ which not only made the suffragettes 'more covert' but brought them into conformity with the definition of CSMNs suggested earlier. Illegal actions were planned in secrecy during $t_{5}$ and those involved in them sought to remain anonymous to all but a select few both before and after their execution. This affords us an opportunity to explore the impact of covertness upon network structure and more specifically to test ideas suggested in the secrecy-efficiency literature reviewed above. We can compare network structure at $t_{5}$ with network structure during the preceding four phases. There are limitations to the data, however.

Firstly, most members of our sample were only in court on one occasion and only a very small proportion were in court on more than four occasions. Consequently, the set of actors for each of our periods is different. Only one activist was active in all five phases compared to 1003 (83\%) who were active in one period only. Of course activists may have been involved in other, legal suffragette activity both before and after their involvement in illegal activity but we have no record of this and must be mindful of turnover in our analysis.

Secondly, our data for $t_{5}$ are different from $t_{1-4}$ in the respect that suffragettes in this latter period were often seeking to avoid arrest. We can be confident for phases $t_{1-4}$ that our data capture the majority of activists involved in illegal activity because the purpose of breaking the law was to generate a court case. This may apply to some acts/actors in $t_{5}$ but it does not apply to all of them. However, it does appear from the wider literature that suffragettes arrested for arson and bomb offences during $t_{5}$ were often arrested at or close to the scene, such that the circumstances of their arrest were similar to those for periods $t_{1-4}$ (Raeburn, 1973; Rosen, 1974; Bearman, 2007a,b).

Thirdly, in all cases we only have data regarding those involved directly in law breaking itself, not those who might have aided, directed or supported them. This applies equally across the time periods and, in that respect, does not prevent us from making meaningful comparisons but we should be mindful of it when seeking to draw conclusions. Suffragette historians disagree about the extent to which militants acted 'under orders' (Bearman, 2007b; Purvis, 2002) but it is clear that in some cases they did and that those who gave the orders were not arrested - or at least were not arrested in the same operation as those whom they ordered - and so would not figure alongside their 'foot soldiers' in the data even if, technically, they belong to the same action set. Furthermore, there is historical evidence of networks whose members supported and helped those involved in illegal actions without being involved in those same actions themselves and thus not necessarily featuring in our courtroom data (Raeburn, 1973; Van Wingerdon, 1999). There was, for example, a network of safe-houses for suffragettes on the run, and places where those weakened by hunger striking could recover (Raeburn, 1973).
Finally, we are only looking at one tie-type (action ties) within a multiplex network. Action ties are very important. They directly support the activist at their moment of maximum vulnerability and there is good evidence to suggest that this often generated a special bond between suffragettes; many co-participants became very good friends and enjoyed a strong sense of identification and esprit de corps (Crawford, 2005; Purvis, 1995, 2000; Stanley and Morley, 1988). However, what we find with respect to these ties may be very different from what we would have found if we were able to map money/authority flows, friendship, etc.

These limits are significant and require that we qualify any conclusions we arrive at. However, they do not completely negate the value of the data so long as we are mindful of them. Furthermore, data on covert networks are always likely to be beset by such limitations, given the efforts of network members to keep their identities, activities and ties secret. What we have is a good enough basis upon which to begin to test and explore the ideas advanced by advocates of the secrecy/efficiency trade off.

It is important to reiterate, moreover, that the research process involved extensive investigation of the existing secondary literature and, indeed, of a wide number of further archival sources including diaries, letters and police reports. ${ }^{9}$ Whilst this additional work does not allow us to correct any of the flaws in our data it has informed our handling and interpretation of it in a manner which we believe to have been beneficial.

\section{Hypotheses}

A key claim of the trade off theory, discussed above, is that the desire of individual actors to maximise their security will motivate them to minimise their activist ties, such that covert networks are characterised by low density. This claim is problematic for a number of reasons, not least because density is sensitive to the order of a network. However, an effort to minimise ties should also lead to a lower average degree, and this is not affected by the order of the network. Therefore we hypothesise that:

\section{H1. Average degree at $t_{5}$ will be lower than at $t_{1-4}$.}

A further extension of this argument, advanced by advocates of the trade off theory, is that organisers and leaders will seek to avoid becoming network hubs. We therefore expect that:

\section{H2. Degree centralisation at $t_{5}$ will be lower than at $t_{1-4}$}

Appearing to challenge this, as noted, other researchers argue that high risk and covert activities require trust, solidarity and the maintenance of oppositional framings and incentive structures, all of which are more likely to emerge and flourish in dense networks (e.g. Coleman, 1988). This argument does not necessarily imply that (global) network density and average degree will increase at $t_{5}$ and is compatible with a drop in both if we find evidence of dense clusters at the local level, such as is suggested in arguments regarding 'cell structure'. We therefore hypothesise that:

H3. $t_{5}$ is characterised by dense localised clusters (akin to cells).

In more direct opposition to trade off theory, however, we observed that some researchers, whilst agreeing that covert networks tend to have a low density, predict high degree centralisation in covert networks (Lindelauf et al., 2009). They argue that the demand for security and secrecy motivates network members to keep path lengths short, because each edge (qua transaction) is a point of vulnerability within a network. If density is low, they continue, this requires that some actors assume a centralised hub

\footnotetext{
${ }^{9}$ We also gathered other network data sets which are not discussed here as they are not relevant (e.g. Edwards and Crossley, 2009; Edwards, forthcoming).
} 
position. This suggests a hypothesis which effectively inverts $\mathrm{H} 2$, suggesting that degree centralisation will be higher at $t_{5}$. It may also be tested independently, however:

H4. Average path lengths between reachable pairs will be shorter at $t_{5}$ than at $t_{1-4}$.

Finally, we will consider Erikson's (1981) claim that, for reasons of security, covert networks recruit disproportionately from amongst pre-existing ties. Assuming that activists would have exhausted that recruitment pool by 1913, we predict that:

H5. The number of new entrants to the network will drop at $t_{5}$ because the network will be increasingly closed to new comers.

and

H6. The number of newly formed ties in the network will drop at $t_{5}$ because activists will only work with those whom they have worked with before and thus know and trust.

\section{Results}

We see in Table 1 that mean degree and degree centralisation (as well as density) drop considerably in $t_{5}$, whilst average path length between reachable pairs rises. This pattern is repeated within the main component for each phase and $t_{5}$ is further distinguished in this respect because its main component involves a much smaller proportion of its order. $\mathrm{H} 1$ and $\mathrm{H} 2$ are supported, therefore, and $\mathrm{H} 4$ is challenged. Our data support the claim that covertness tends to encourage decentralisation and reduction of active ties.

In an effort to test these findings further we identified those activists $(n=75)$ who were in court both during $t_{5}$ and at some point between $t_{1}$ and $t_{4}$, comparing their ties for $t_{5}$ to those for $t_{1-4}$ (Table 2). The pattern is the same. Average degree and degree centralisation both drop (along with density). Average path length between reachable pairs did not grow in this case but that is because the network in $t_{5}$ comprises multiple small components, each with only a few members and, consequently, short path lengths.

Again then, $\mathrm{H} 1$ and $\mathrm{H} 2$ are supported. We should remain mindful of the limitations of our data here and, in particular, of the fact that: (1) we only have data regarding one tie type; (2) we only have data regarding suffragettes who were tried for illegal protest activity and; (3) attempts to avoid arrest were greater at this period. However, our findings offer some support for the claim that the demand for secrecy tends to encourage both decentralisation and a limiting of the number of active ties in a network.

Table 1 also points to a proliferation of isolates, dyads and components at $t_{5}$. The network is not only becoming more sparse and decentralised. It is dividing into components. Action sets are no longer overlapping. The growth in the number of isolates challenges H3. $16 \%$ of those tried in this period were tried alone, a substantial increase on previous periods. However, this may reflect the shift in suffragette tactics towards evasion of the police and avoidance of arrest. Members of covert action sets may have been arrested alone even if they did not act alone, whereas previously all members of an action set would have been arrested together. Furthermore, 16\% is not a huge number and, as the graph in Fig. 6 illustrates, the $84 \%$ who were not isolates tended to form small, sometimes interlocking clusters, not unlike one type ${ }^{10}$ of 'cell structure'. This offers some support to H3.

The localised density suggested in Fig. 6 is confirmed by the clustering, weighted clustering and transitivity co-efficients for $t_{5}$ $(0.932,0.907$ and $76.52 \%$, respectively (isolates removed)). These figures must be treated with caution. Our network is derived from

10 There are several possible cell structures. See footnote 5.

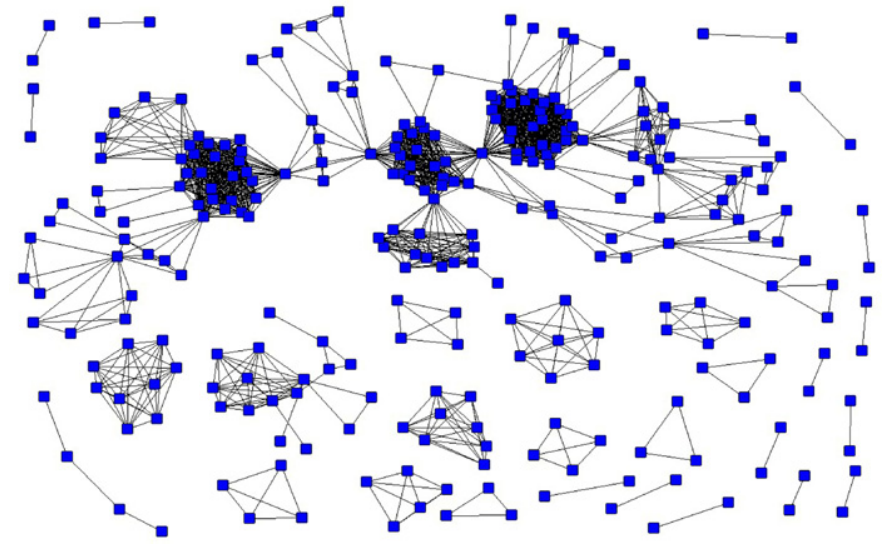

Fig. 6. Court appearance network at $t_{5}$, minus isolates.

a two-mode incidence matrix such that clustering is to be expected. It is an artefact of our method. However, given that we linked activists on the basis of their co-participation in high risk activities, there is good reason to suppose that our clusters are genuinely cohesive groupings and thus that density is high at the local level. Furthermore, the mean size of action sets drops significantly at $t_{5}$, even when isolates are removed, allowing for the possibility that actors developed strong ties with all of their co-participants. This is compatible with and lends some support to $\mathrm{H} 3$.

As they became more militant and more covert suffragettes operated in smaller, largely unconnected action sets. This reduced the global density of their network whilst preserving localised density in individual components. This is consistent with the basic constituents of a 'cell structure', although we do not have a neat cell structure, by any means, nor is there any suggestion that the suffragettes deliberately sought to implement one. It also resonates very strongly with the idea of 'leaderless resistance'. Distinct action sets appear now to be acting independently of one another. These findings are also consistent with claims regarding the importance of (local) density and closure in high risk and extreme activism (e.g. Coleman, 1988, 1990).

It may be argued that the proliferation of components at $t_{5}$ is as much an effect of a crisis of leadership within the WSPU as of any increased desire for covertness. The organisation folded in 1914 (14 years before women were granted a vote on the same terms as men), ostensibly in response to the start of the First World War but following a period in which key organisational figures had been 'purged', resulting in losses of both organisational capacity and grassroots legitimacy. The lack of connection between action sets may therefore be a consequence of the fact that action was no longer being coordinated effectively from above. Even if this is so, however, the pattern remains consistent with the claim that network members seek to minimise ties when issues of secrecy and security come to the fore and we know from archival research (e.g. Raeburn, 1973) that activists were increasingly drawing upon covert and counter-surveillance repertoires at this point.

Again our findings must be qualified by reference to the methodological limitations of the study. It is also possible that the proliferation of components is more apparent than real, reflecting the fact, for example, that more suffragettes escaped detection during $t_{5}$. There is nothing in our data which appear to refute arguments regarding cell structures and leaderless resistance, however, and much that is consistent with it.

Turning finally to the role of pre-existing ties, neither $\mathrm{H} 5$ nor $\mathrm{H} 6$ is supported. $77 \%$ of those tried in $t_{5}$ were tried for the first time during that period, a figure which is lower than for $t_{1}$ and $t_{2}$ but slightly higher than for $t_{3}$ and $t_{4}$ (Table 3 ). A similar number of new people were entering the network at this time, therefore. To test 
Table 1

Basic network measures, $t_{1-5}$.

\begin{tabular}{|c|c|c|c|c|c|c|}
\hline & $t_{1}$ & $t_{2}$ & $t_{3}$ & $t_{4}$ & $t_{5}$ & Whole period \\
\hline Order (i.e. number of nodes) & 149 & 404 & 175 & 434 & 328 & 1213 \\
\hline Components with order $>2$ & 1 & 3 & 1 & 3 & 14 & 9 \\
\hline Components with order $=2$ & 0 & 3 & 0 & 3 & 14 & 11 \\
\hline Isolates & 4 & 12 & 8 & 19 & 52 & 63 \\
\hline Density & 0.39 & 0.14 & 0.53 & 0.09 & 0.03 & 0.05 \\
\hline Mean path length between reachable pairs & 1.73 & 2.28 & 1.46 & 2.4 & 3.57 & 2.5 \\
\hline Mean degree (SD) & $58(27)$ & $57(52)$ & $92(42)$ & $40(29)$ & $9(11)$ & $56(57)$ \\
\hline Degree centralisation (\%) & 47.66 & 34.23 & 34.53 & 22.7 & 14.05 & 29.05 \\
\hline Order of main component (\% of total order) & $145(97)$ & $367(91)$ & $167(95)$ & $402(93)$ & $169(52)$ & $1090(90)$ \\
\hline Density of main component & 0.42 & 0.17 & 0.58 & 0.11 & 0.09 & 0.06 \\
\hline Degree centralisation of main component & 47.86 & 36.22 & 33.54 & 23.82 & 23.59 & 31.78 \\
\hline
\end{tabular}

Table 2

$t_{5}$ nodes with and without previous involvement.

\begin{tabular}{|c|c|c|c|}
\hline & \multicolumn{2}{|c|}{$t_{5}$ nodes with $t_{1-4}$ involvement } & \multirow{2}{*}{$\begin{array}{l}t_{5} \text { nodes with no prior involvement } \\
t_{5} \text { ties }\end{array}$} \\
\hline & $t_{1-4}$ ties & $t_{5}$ ties & \\
\hline Order & 75 & 75 & 256 \\
\hline Components $>2$ & 2 & 5 & 18 \\
\hline Isolates & 5 & 26 & 50 \\
\hline Dyads & 0 & 6 & 11 \\
\hline Density & 0.13 & 0.04 & 0.03 \\
\hline Mean degree (SD) & $10(8)$ & 3.28 & 7.359 \\
\hline Degree centralisation (\%) & $31 \%$ & $16 \%$ & $9 \%$ \\
\hline Order of main component ( $\%$ of total order) & $66(88 \%)$ & $21(28 \%)$ & $57(22)$ \\
\hline
\end{tabular}

Table 3

New nodes and ties.

\begin{tabular}{|c|c|c|c|c|c|}
\hline & \multicolumn{2}{|c|}{ All nodes active in stated period } & \multicolumn{3}{|c|}{ Nodes active in stated period and with previous involvement } \\
\hline & $\begin{array}{l}\% \text { of nodes new to } \\
\text { campaign }\end{array}$ & $\begin{array}{l}\text { \% of ties at each time } \\
\text { point not observed } \\
\text { previously }\end{array}$ & Order & $\begin{array}{l}\text { \% of ties observed in } \\
\text { earlier waves but not in } \\
\text { current wave }\end{array}$ & $\begin{array}{l}\% \text { of ties at each time } \\
\text { point not observed } \\
\text { previously }\end{array}$ \\
\hline$t_{1}$ & 100 & 100 & $\mathrm{n} / \mathrm{a}$ & $\mathrm{n} / \mathrm{a}$ & $\mathrm{n} / \mathrm{a}$ \\
\hline$t_{2}$ & 94 & 99.9 & 26 & 91 & 48 \\
\hline$t_{3}$ & 72 & 96.9 & 50 & 41 & 84 \\
\hline$t_{4}$ & 71 & 96.9 & 126 & 89 & 70 \\
\hline$t_{5}$ & 77 & 98.8 & 75 & 95 & 86 \\
\hline
\end{tabular}

for new ties we identified the number of ties at $t_{5}$ between parties who had not previously appeared in court together, comparing this measure of new ties with the same measure for each preceding period. The proportions are consistently high across all periods, and no less so for $t_{5}$. Contrary to H6, as many new action ties were formed in $t_{5}$ as in each of the preceding phases.

To test whether new ties were accounted for by new network members, with established activists perhaps electing to work disproportionately with those they had worked with before (a finding which would lend some support to the idea of pre-existing ties), we identified, for periods $t_{2-5}$, all of those active in a period who had also been active in a prior period, comparing their ties from previous periods to their ties in the current period (Table 3 ). The analysis suggests that a large proportion of the ties an activist has in any given period are new to that period. And this is no less true of $t_{5}$. Again this conflicts with our hypotheses regarding new tie formation.

Furthermore, of the 52 isolates in $t_{5}$ only 26 (50\%) are newcomers, when newcomers actually make up $77 \%$ of the nodes in the network. In effect, the odds of being an isolate increase for those who have been active previously (odds ratio $=3.37$ ). We could speculate on the reasons for this. Perhaps more experienced activists have the confidence to act alone. Perhaps newcomers only become involved because they have been recruited into teams. And we do not know what other types of tie are in play here. However, our data appear to refute $\mathrm{H} 5$ and $\mathrm{H} 6$. Our network was no more dependent upon either pre-existing nodes or pre-existing ties at $t_{5}$ than in any period prior to it.

As with all of our findings we must qualify these claims by reference to the limitations of the data. We only know of the arrests of the activists in our sample and therefore do not know how new our 'newcomers' were to the movement as a whole or indeed what ties they and the members of our 'old guard' enjoyed other than that of co-participants in particular militant actions. However, the evidence we have challenges claims regarding the importance of pre-existing ties.

\section{Concluding discussion}

In this paper we have derived and tested a number of hypotheses drawn from on-going debates regarding the structure of covert social networks, using data on the UK suffragettes. We identified theoretical and methodological problems with the idea that activists trade efficiency for secrecy and that this generates networks which are sparse and degree decentralised. However, our data offer support for that those claims. Average degree dropped in suffragette action networks and these networks became less degree centralised as they became more covert.

Competing claims regarding the importance of network cohesion were not thereby completely rejected, however. We suggested that a drop in global density does not necessarily preclude localised density, and an analysis of transitivity and clustering in our most 
covert network bore this out. Although there was an increase in the number of isolates when our network became covert, those nodes which were not isolates tended to form small, dense clusters.

We have indicated that this clustering is of relevance to debates on cell structure in covert networks. However, we emphasise that our clusters were in many instances independent components and, as such, do not correspond to either the hierarchical cell structure introduced by PIRA in the 1970s (Maloney, 2002), which involved each cell receiving commands from the centre, nor the overlapping affinity groups favoured by anarchists. Insofar as our $t_{5}$ network manifests a cell structure it is of the atomised variety described in the literature on 'leaderless resistance' (Sageman, 2008).

These are important conclusions but they must be regarded with caution. The networks analysed in this paper focus upon one tie type only within a movement whose constitutive ties were multiplex. The ties that we have looked at are important, involving, as they do, co-participation in 'high risk' operations. But the picture we have painted may look different if other ties were taken into consideration. Furthermore, examining court data affords us only a partial glimpse into a covert world and its constitutive networks. We know from historical sources of other activities and networks involved in the covert activity of the suffragettes that we have not captured here and do not have the data to capture. We know that suffragettes operated safe houses, for example, and we have many fragments of evidence regarding the help that those on the run received from their comrades. The evidence that we have at least allows us a glimpse of the effect of an increase in level of covertness upon network structure, however, which future work will hopefully build upon.

\section{References}

Adams, J., 1986. The Financing of Terror. Simon and Schuster, New York.

Asal, V., Rethemeyer, R., 2006. Researching terrorist networks. Journal of Security Education 1 (4), 65-74.

Baker, W., Faulkner, R., 1993. The social organisation of conspiracy: illegal networks in the heavy electric equipment industry. American Sociological Review 58 (6), $837-860$.

Barnes, J., 1971. Networks and political process. In: Mitchell, J.-C. (Ed.), Social Networks in Urban Situations. Manchester University Press, Manchester, pp. 51-74.

Beam, L., 1992. Leaderless resistance. The Seditionist 12, www.louisbeam. com/leaderless.htm.

Bearman, C., 2005. An examination of suffragette violence. English Historical Review CXX (486), 365-397.

Bearman, C., 2007a. Confronting the suffragette mythology. BBC History Magazine February, 16-18.

Bearman, C., 2007b. An army without discipline. The Historical Journal 50 (4), $861-889$.

Borgatti, S.P., Everett, M.G., Freeman, L.C., 2002. Ucinet for Windows. Analytic Technologies, Harvard, MA.

Carley, K., Dombroski, M., Tsvetovat, Reminga, J., Kamneva, N., 2003. Destabilising Dynamic Covert Networks. In: Proceedings of the 8th International Command and Control Research and Technology Conference, Washington.

Coleman, J., 1988. Free riders and zealots: the role of social networks. Sociological Theory 6 (1), 52-57.

Coleman, J., 1990. The Foundations of Social Theory. Harvard University Press, Cambridge.

Crawford, E., 1999. The Women's Suffrage Movement, Reference Guide 1866-1928. Routledge, London.

Crawford, E., 2005. Police, prisons and prisoners: the view from the home office. Women's History Review 14 (3 and 4), 487-506.

Crossley, N., 2002. Making Sense of Social Movements. Open University Press, Buckinghamshire.

Crossley, N., 2007. Social networks and extra-parliamentary politics. Sociology Compass 1 (1), 222-236.

Diani, M., McAdam, D., 2003. Social Movements and Networks. Oxford University Press, Oxford.

Edwards, G. Infectious innovations? The diffusion of tactical innovation in social movement networks, the case of suffragette militancy. Social Movement Studies, forthcoming.

Edwards, G., Crossley, N., 2009. Measures and meanings: exploring the ego-net of Helen Kirkpatrick Watts, militant suffragette. Methodological Innovations OnLine 4, 37-61.

Enders, W., Su, X., 2007. Rational terrorists and optimal network structure. The Journal of Conflict Resolution 51 (1), 33-57.
Erikson, B., 1981. Secret societies and social structure. Social Forces 60 (1), $188-210$.

Feld, S., 1981. The focused organisation of social ties. American Journal of Sociology 86, 1015-1035.

Feld, S., 1982. Social structural determinants of similarity among associates. American Sociological Review 47, 797-801.

Fowler, R., 1991. Why did suffragettes attack works of art? Journal of Women's History 2 (3), 109-124.

Garfinkel, S., 2003. Leaderless resistance today. First Monday 8 (3), http://firstmoday.org.

Goffman, E., 1959. The Presentation of Self in Everyday Life. Harmondsworth, Penguin.

Goffman, E., 1969. Strategic Interaction. University of Pennsylvania Press, Philadelphia.

Granovetter, M., 1973. The strength of weak ties. American Journal of Sociology 78 (6), 1360-1380.

Granovetter, M., 1983. The strength of weak ties revisited. Sociological Theory 1, 201-233.

Harnden, T., 1998. Bandit Country. Hodder and Stougton, London.

Harnden, T., 1999. Bandit Country. Hodder and Stroughton, London.

Holton, S., 1988. Feminism and Democracy. Cambridge University Press, Cambridge.

Home Office, 1922. Suffragettes, Index of Names of Persons Arrested, 1906-1914 National Archives, Reference: HO45/24665/253239.

Jenkins, C., 1983. Resource mobilisation theory and the study of social movements. Annual Review of Sociology 9, 527-553.

Kay, J., 2008. It wasn't just Emily Davison! International Journal of the History of Sport 25 (10), 1338-1354.

Klerks, P., 2001. The network paradigm applied to criminal organisations. Connections 24 (3), 53-65.

Koschade, S., 2006. A social network analysis of Jemaah Islamiyah. Studies in Conflict and Terrorism 29, 559-575.

Krebs, V., 2001. Mapping networks of terrorist cells. Connections 24 (3), 43-52.

Krebs, V., 2002. Uncloaking terrorist networks. First Monday 4 (1), http://131.193.153.231/www/issues/issue7_4/krebs/index.html (accessed 22.06.09).

Lindelauf, R., Borm, P., Hamers, H., 2009. The influence of secrecy on the communication structure of covert networks. Social Networks 31, $126-137$.

Maloney, E., 2002. The Secret History of the IRA. Norton and Co, London.

Mitchell, D., 1977. Queen Christabel. Macdonald and Jane's, London.

Monoghan, R., 2000. Single issue terrorism. Studies in Conflict and Terrorism 24 (4), 255-265.

Morselli, C., 2009. Inside Criminal Networks. Springer, New York.

Morselli, C., Giguère, C., Petit, K., 2007. The efficiency/security trade-off in criminal networks. Social Networks 29, 143-153.

Phillips, M., 2003. The Ascent of Woman. Abacus, London.

Purvis, J., 1995. The prison experiences of the suffragettes in Edwardian Britain. Women's History Review 4 (1), 103-133.

Purvis, J., 2000. Deeds not words. In: Purvis, J., Holton, S. (Eds.), Votes for Women. Routledge, London, pp. 135-158.

Purvis, J., 2002. Emmeline Pankhurst. Routledge, London.

Raab, J., Milward, H., 2003. Dark networks as problems. Journal of Public Administration Research and Theory 13 (4), 413-439.

Raeburn, A., 1973. The Militant Suffragettes. Victorian (and Modern) History Bookclub, Newton Abbott.

Rodriguez, J., 2009. Weakness and strengths of terrorist networks: The Madrid March 11 Attacks. Paper presented at the Annual Meeting of the American Sociological Association. Available at http://www.allacademic. com/meta/p243052_index.html.

Rosen, A., 1974. Rise Up Women!. Routledge and Kegan Paul, London.

Rosenthal, N., Fingritd, M., Ethier, M., Karant, R., McDonald, D., 1985. Social movements and network analysis. American Journal of Sociology 90, 1022-1054.

Sageman, M., 2004. Understanding Terror Networks. University of Pennsylvania Press, Philadelphia.

Sageman, M., 2008. Leaderless Jihad. University of Pennsylvania Press, Philadelphia.

Simmel, G., 1906. The sociology of secrecy and secret societies. American Journal of Sociology 11 (4), 441-498.

Smith, H., 1998. The British Women's Suffrage Campaign 1866-1928. Longman, London.

Sparrow, M., 1991. The application of network analysis to criminal intelligence. Social Networks 13, 251-274.

Stanley, L., Morley, A., 1988. The Life and Death of Emily Wilding Davison. The Women's Press, London.

Stevenson, R., Crossley, N. Covert social movement networks in context: exploring change in the inner circle of the Provisional Irish Republican Army. Social Movement Studies, forthcoming.

Stohl, M., 2008. Networks, terrorists and criminals. Crime, Law and Social Change $50,59-72$

Tsvetovat, M., Carley, M., 2005. Structural Knowledge and Success of Anti-Terrorist Activity. Journal of Social Structure 6 (2)

Van Wingerdon, S., 1999. The Women's Suffrage Movement in Britain, 1866-1929. Palgrave, Basingstoke. 